\title{
Erratum to: Autism Developmental Profiles and Cooperation with Oral Health Screening
}

\author{
Rennan Y. Du ${ }^{1}$ Cynthia K. Y. Yiu ${ }^{1}$ - Virginia C. N. Wong ${ }^{2} \cdot$ Colman P. McGrath $^{3}$
}

Published online: 5 October 2015

(c) Springer Science+Business Media New York 2015

Erratum to: J Autism Dev Disord (2015) 45:2758-2763

DOI 10.1007/s10803-015-2416-7

In the original version of the article, the middle name of one of the coauthors is published incorrectly. The author name should be Cynthia K. Y. Yiu.

Also, a reference citation and the reference are missing in the caption of Table 1 . The table caption and missing reference are given below.
Table 1 Criteria for assessing the developmental levels of children with ASD (Kokina and Kern 2010).

\section{Reference}

Kokina, A., \& Kern, L. (2010). Social Story ${ }^{\mathrm{TM}}$ interventions for students with autism spectrum disorders: A meta-analysis. Journal of Autism and Developmental Disorders, 40(7), 812-826.

The online version of the original article can be found under doi:10.1007/s10803-015-2416-7.

Colman P. McGrath

mcgrathc@hkucc.hku.hk

1 Faculty of Dentistry, The University of Hong Kong,

Hong Kong SAR, China

2 Department of Paediatrics and Adolescent Medicine, Li Ka Shing Faculty of Medicine, The University of Hong Kong, Hong Kong SAR, China

3 3B12, Dental Public Health, Periodontology and Public Health, Faculty of Dentistry, The University of Hong Kong, 34 Hospital Road, Sai Ying Pun, Hong Kong SAR, China 